\title{
Analysis of Instability Mechanism and Induced Cause of Urban Pavement in Xining City, China
}

\author{
Gan Qi, ${ }^{1}$ Zhenyu Wang ${ }^{(D,},{ }^{1,2}$ Yu Chen $\left(D,{ }^{3}\right.$ Chun Zhu, ${ }^{4,5}$ Dazhong Ren, ${ }^{5}$ Tao Tian, ${ }^{6}$ and Fu Yang ${ }^{6}$ \\ ${ }^{1}$ China Institute of Geo-Environment Monitoring, Beijing 100081, China \\ ${ }^{2}$ State Key Laboratory of Deep Rock Mechanics and Underground Engineering, Beijing 100083, China \\ ${ }^{3}$ Research Institute of Geotechnical Engineering, Hohai University, Nanjing 210098, Jiangsu, China \\ ${ }^{4}$ School of Earth Sciences and Engineering, Hohai University, Nanjing 210098, China \\ ${ }^{5}$ Shanxi Key Laboratory of Advanced Stimulation Technolgy for Oil \& Gas Reservoirs, College of Petroleum Engineering, \\ Xi'an Shiyou University, Xian 710065, China \\ ${ }^{6}$ Key Lab of Coal Resources Exploration and Comprehensive Utilization, MNR, Shanxi Coal Geology Group Co.,Ltd., \\ Xi'an 710021, China \\ Correspondence should be addressed to Yu Chen; yuchen0420@hhu.edu.cn
}

Received 26 November 2021; Revised 13 December 2021; Accepted 24 January 2022; Published 8 February 2022

Academic Editor: Abílio De Jesus

Copyright ( 2022 Gan Qi et al. This is an open access article distributed under the Creative Commons Attribution License, which permits unrestricted use, distribution, and reproduction in any medium, provided the original work is properly cited.

\begin{abstract}
As a large human gathering place, the city directly causes huge property losses and casualties due to the ground collapse accident every year. In order to explore the causes and damage characteristics of urban ground collapse, taking Xining City, Qinghai Province, as an example, this paper analyzes the accidental factors causing ground collapse through on-site geological exploration and then expounds the deformation characteristics of urban ground collapse by using the numerical simulation method of Fluent and PFC. Using the collapsible balance method, it is obtained that the insufficient thickness of the top plate of the Loess Soil Subgrade in the collapse pit area is the inevitable factor causing the final collapse. The results show the following: (1) The failure of water supply pipe is an accidental factor leading to the formation of underground cavity, and the ground collapse accident is hidden, sudden, and of high risk, and its deformation and failure development process is slow. (2) The critical thickness of the roof above the air raid shelter is about $22 \mathrm{~m}$, and the actual thickness is about $11.6 \mathrm{~m}$, which is prone to deformation and uneven settlement, which is also an inevitable factor causing ground collapse. (3) The numerical simulation study shows that the final formation deformation range is about $16 \mathrm{~m}$. At this time, the height of the formed cavity is about $9 \mathrm{~m}$. The plastic zone tends to develop around, and the maximum settlement position appears above the air raid shelter. (4) The collapse process includes four stages: water supply pipeline leakage, underground cavity formation, collapse critical state, and ground collapse. This research and analysis provides theoretical guidance and scientific basis for the investigation, measurement, detection, and monitoring of various underground pipe networks of urban roads.
\end{abstract}

\section{Introduction}

Ground collapse refers to a phenomenon or process caused by the downward collapse of surface rocks and soil under the influence of natural factors or human engineering activities, as well as the formation of collapse pits (holes) on the ground. Generally, there are four types: karst collapse [1-4], goaf collapse [5-7], loess collapse [8-11], and engineering collapse [12]. With the vigorous development of China's modernization, cities are mainly characterized by concentrated population and dense buildings. Different from the ground subsidence with large scope and small deformation, the pavement collapse has the characteristics of great destructiveness, high concealment, and sudden occurrence. In the process of urban road collapse, human activities play an important role, and, at the same time, its occurrence usually brings great influence on human society [13]. Once the road collapse occurs in urban areas, it will often cause road damage, which may cause traffic congestion at least or heavy property losses and casualties. For example, 
on February 7, 2018, the tunnel segment was damaged and the ground collapsed at the construction site of the right line of the Lvdaohu-Huyong shield tunneling section of Foshan Metro Line 2 due to flooding. The collapse pit was about $30 \mathrm{~m}$ long, resulting in 10 deaths and 1 loss of contact. At the same time, the ground collapse in the urban area will increase the uneven settlement of the surrounding building foundations in the collapsed area and even lead to the collapse of the building [14]. The 2011-2020 National Land Subsidence Prevention and Control Plan, jointly compiled by the Ministry of Land and Resources, the Ministry of Water Resources, the Development and Reform Commission, the Ministry of Finance, and ten other ministries and commissions, points out that there are currently more than 50 cities in the country suffering from land subsidence disasters, distributed in Beijing, Tianjin, and Shanghai. In Jiangsu, Hebei, Shanxi, Inner Mongolia, and 20 other provinces, autonomous regions, and municipalities, the country's cumulative land subsidence of more than 200 millimeters reached 79,000 square kilometers, and there is a trend of further expansion, of which the Yangtze River Delta, the North China Plain, and the Fenwei Basin are the most prominent. According to the statistical data of the "China Statistical Yearbook," in the past five years, our country has experienced 966 ground collapse disasters, and an average of about 300 people die from the disaster every year. Strictly speaking, ground collapse and collapse, mudslides, landslides, and so forth are all typical geological disasters. There are many factors that induce pavement collapse in urban areas, and water is usually the main factor, including groundwater action and surface water infiltration. Secondly, loess, when it meets water, has collapsibility effect and forms collapse [15]. Water mainly causes collapsibility, erosion, differential pressure, and so forth $[16,17]$. Under the action of infiltration, the soil is prone to two failure modes, namely, pipe gushing and soil flow [18]. Under the action of water seepage, the fine-grained soil in the soil is washed away by water, and the remaining large particles form a soil skeleton with poor stability and easy instability, forming the initial underground pores [19]. Yechieli et al. [15] studied over 4000 sinkholes in Israel and found that their formation is related to the shrinking underground system around the Dead Sea. Selleri et al. [20] studied the Karst landform of Salento Peninsula and found that groundwater and surface water were the main factors causing multiple sudden subsidence. Ouyang [21] believes that the ground collapse process is divided into four stages: groundwater level drop, cavern formation, cavern expansion, and ground collapse formation. Among them, the seepage force generated by underground underwater seepage is the power source of ground collapse. Cao, Peng et al., Gao, $\mathrm{Hu}$, and others found through research that ground collapse is mainly related to groundwater and surface water activities [22-25]. Rock integrity also weakens under repeated wetting conditions over long periods of time [26]. At the same time, cyclic rainfall will also affect the physical and mechanical properties of rock mass deformation [27].

Urban underground construction activities have destroyed the original stable state of the soil, and a little carelessness will cause the ground to collapse. For example, during the construction of Kurtkulag irrigation tunnel, many ground collapse accidents occurred mainly at the exit and entrance of the tunnel and the location where the tunnel crosses the fault [28]; Hou et al. [29] pointed out that the existence of underground holes greatly reduced the strength of the ground and the ability of resisting subsidence and divided Beijing subway accidents into five categories. Ma et al. [30] analyzed the causes of three consecutive ground collapses in a subway tunnel within half a month after the start of the shield machine and found that the causes of ground collapses in the process of shield construction mainly include four aspects: engineering geological conditions, auxiliary engineering quality problems, excavation management, and shield machine failure.

Xining has a semiarid climate on a continental plateau with an average annual rainfall of $380 \mathrm{~mm}$. Huangshui and its tributaries, Nanchuan River and Beichuan River, converge in the urban area from west, south, and north and flow through the city to the east. Xining City, as the political, economic, scientific, educational, cultural, transportation, and communication center of Qinghai Province, has seen at least 14 road collapse accidents since 2014, which seriously threatened the lives and properties of urban residents. Through detailed investigation and research on road collapse accidents in urban areas, not only can corresponding measures be taken against road collapse accidents, but also they have long-term significance in preventing such incidents from recurring throughout the country.

In this study, through the investigation of the geological and hydrological conditions and the collapse situation of the pavement collapse area in Xining City on January 13, the critical roof thickness of loess-like soil subgrade in the collapse pit area was calculated and analyzed by using the numerical simulation method of Fluent and PFC joint calculation. Finally, the cause of collapse and failure mechanism are analyzed in combination with the field situation. In addition, this paper also puts forward reasonable suggestions and measures to reduce the occurrence of such disasters again and do a good job of deformation monitoring between the collapse pit and surrounding buildings to prevent secondary damage [31]. The formation of collapse pit reduces the stability of the inner pit, so the inner wall of collapse pit should be monitored and strengthened in time [32].

\section{Engineering Geological Conditions}

2.1. Study Area. The road collapse accident that occurred on January 13, 2020, was at the Red Cross Bus Station at the entrance of the Great Wall Hospital, South Street, Chengzhong District, Xining City (Figure 1). The cavity formed after the collapse is nearly elliptical cone-shaped, with a diameter about 9-10 meters, a visible depth about 8-10 meters, and a ground area about 80 square meters (Figure 2). On its east side wall, there are buried water supply pipes, cables, gas, and other pipes network. The water supply pipe network, communication cables, and gas pipe network 


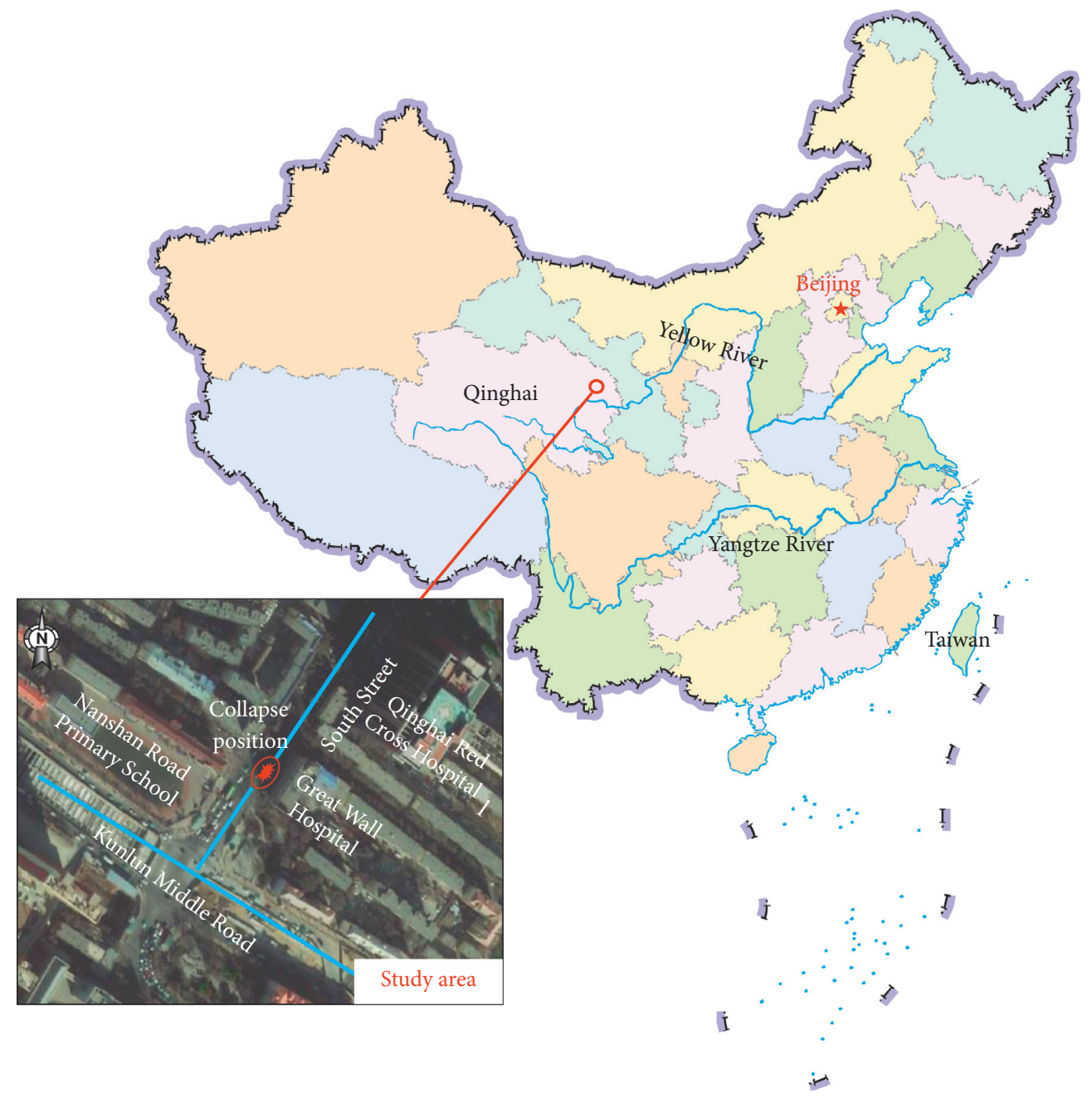

FIGURE 1: Location map of the collapsed area.

spread out in the north-south direction are buried 1.5-2 meters deep, and the power supply pipeline network spread out in the east-west direction is $2-4$ meters deep. The accident resulted in the bus and train platform collapse into a pit, eventually killing 10 people and injuring 17 .

\subsection{Geomorphological Characteristics. The central area of} Xining City is mainly composed of modern riverbeds and terraces of the main stream of Huangshui River, piedmont alluvial plains, and alluvial plains. The terrain is relatively flat and open, distributed in a belt along the river. The geomorphology is mainly caused by accumulation and erosion. The south bank of the Huangshui River is composed of I-III terraces and is the main concentrated construction area of the city. From the north of the Huangshui River to the south of the first-level terrace, the slope is from 1 to $2^{\circ}$, the secondlevel terrace is from 3 to $5^{\circ}$, and it gradually steepens to the third-level terrace to the south, with a slope of $4-6^{\circ}$, as well as low hills in the south. The front edge of the area has a slope of $25-30^{\circ}$.

The south side of the Huangshui River Valley is a hilly area with beams and ridges, which is strongly eroded by gullies and the terrain is very fragmented. Loess and clastic rocks constitute the main lithology of hilly areas. Loess is mainly covered on the top of the hilly area, and local sections are distributed along the slope of the hillside.

The landform unit in the collapsed area belongs to the third-level terrace on the south bank of the Huangshui River, about $150 \mathrm{~m}$ away from the front edge of the third-level terrace. Due to the construction of the South Street, the original steep ridge was transformed into a road, with a slope of $5-6^{\circ}$ and a nearly east-west direction. The overall terrain is high in the west and low in the east, high in the south, and low in the north. The elevation of the site is $2271.72-2254.52 \mathrm{~m}$, the surface elevation difference is $17.2 \mathrm{~m}$, and the terrain is flat and open; no faults have been found passing through the site after investigation. The underground manned air raid shelter passes through.

2.3. Geological Characteristics. The Xining Basin is located in the Qilian stratigraphic zone. Due to the influence of the strong vertical movement of the crust and the strong transformation of the rivers and piedmont alluvium, the Quaternary system has created the current basin landscape. 

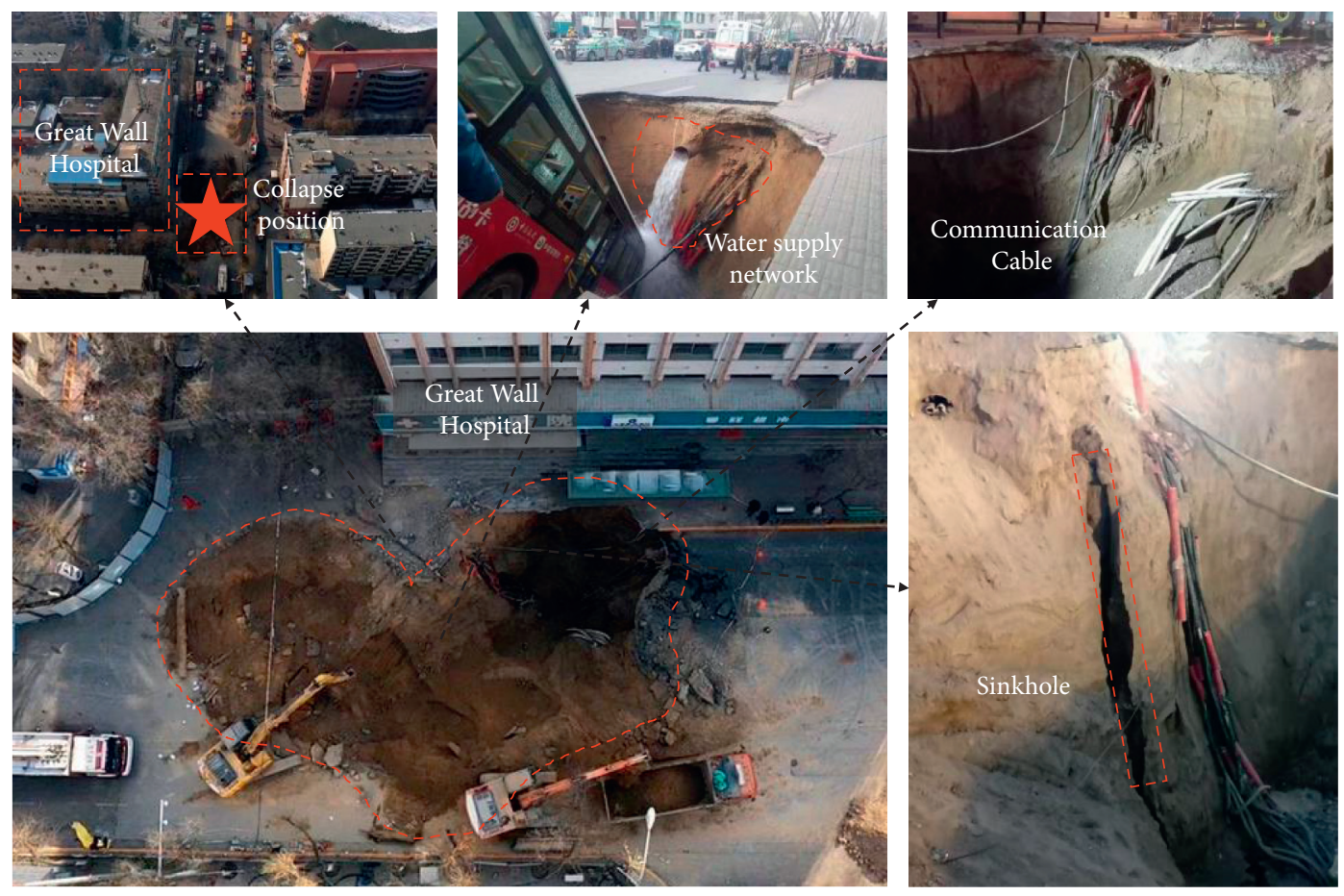

Figure 2: Collapse area situation.

The main exposed strata in the basin are Paleoproterozoic, Triassic, Jurassic, Cretaceous, Paleogene, Neogene, and Quaternary. The Quaternary strata can be divided into alluvial deposits, alluvial proluvial deposits, slope proluvial deposits, and aeolian deposits according to their genetic types.

According to the on-site geological survey, a detailed study of the rock and soil in the collapsed area is carried out (Figure 3). The surface layer is the Quaternary artificial fill, which is mainly composed of earthy yellow and gray-black variegated silt, gravel, construction waste, and a small amount of construction waste. The range is $0.5-3.8 \mathrm{~m}$. The lower layer is tertiary alluvial and alluvial loess-like soil, mainly composed of yellow silt, with needle-like pores, developed vertical joints and fissures, calcareous cementation, poor toughness, and easiness to soften and corrode in contact with water. Collapsibility is divided into collapsible loess (buried depth of about 1.5-10.3 m) and noncollapsible loess (buried depth of about 10.3-11.4 m). The roof of the underground air raid shelter was excavated at a buried depth of 11.6 meters. The third layer is mainly the pebble layer of tertiary lacustrine layer and alluvial layer, composed of bluegray, gray-white sandstone, limestone, quartzite, and a small amount of light-colored metamorphic rock. The pebble layer is also mixed with silty clay layer.

2.4. Hydrogeological Characteristics. The collapse area is located at the front edge of the third terrace on the south bank of the Huangshui River. Quaternary pore water exists on the site. The stable groundwater level is $20.8-29.0 \mathrm{~m}$ and the groundwater elevation is $2233.72-2342.72 \mathrm{~m}$. The groundwater is mainly affected by the complementation of Huangshui River and the south. The recharge of the underground runoff on the side is discharged in the downstream area in the form of torrents, and the groundwater flows from the southwest to the northeast and is finally discharged to the Huangshui River. The dynamic changes are seasonally obvious, and the annual water level change range is about $1.0-1.5 \mathrm{~m}$.

\section{Causes and Mechanism of Collapse}

According to the public meteorological data, there is no obvious precipitation process from December 2019 to the afternoon of January 13, 2020. The surface pavement in the surface area is covered by asphalt concrete, and the permeability is poor. Therefore, the formation of collapse pit can exclude the influence of groundwater and surface water. According to the on-site infiltration and collapse inspection, the water supply pipe which was wrongly broken on the east side of the pit wall had a buried depth about $1.5 \mathrm{~m}$, a diameter of $50 \mathrm{~cm}$, and a wall thickness of $0.6 \mathrm{~cm}$. The material is cast iron. A water drop hole with a diameter about $0.8 \mathrm{~m}$ and a depth about 7 meters is formed at the lower part.

3.1. Engineering Geological Structure Model. After the accident, through the detailed investigation of the spatial structure of the collapse location, it is determined that there is an air raid shelter with a width of $1.5 \mathrm{~m}$ and a height of $2.5 \mathrm{~m}$ at the depth of $11.6 \mathrm{~m}$ from the ground, which is a rubble precast arch structure, and the location is roughly coincident with the collapse area. Combined with the results of geological survey of hydraulic engineering environment, based on the geomorphic unit as the main division basis, considering the characteristics of geotechnical engineering 


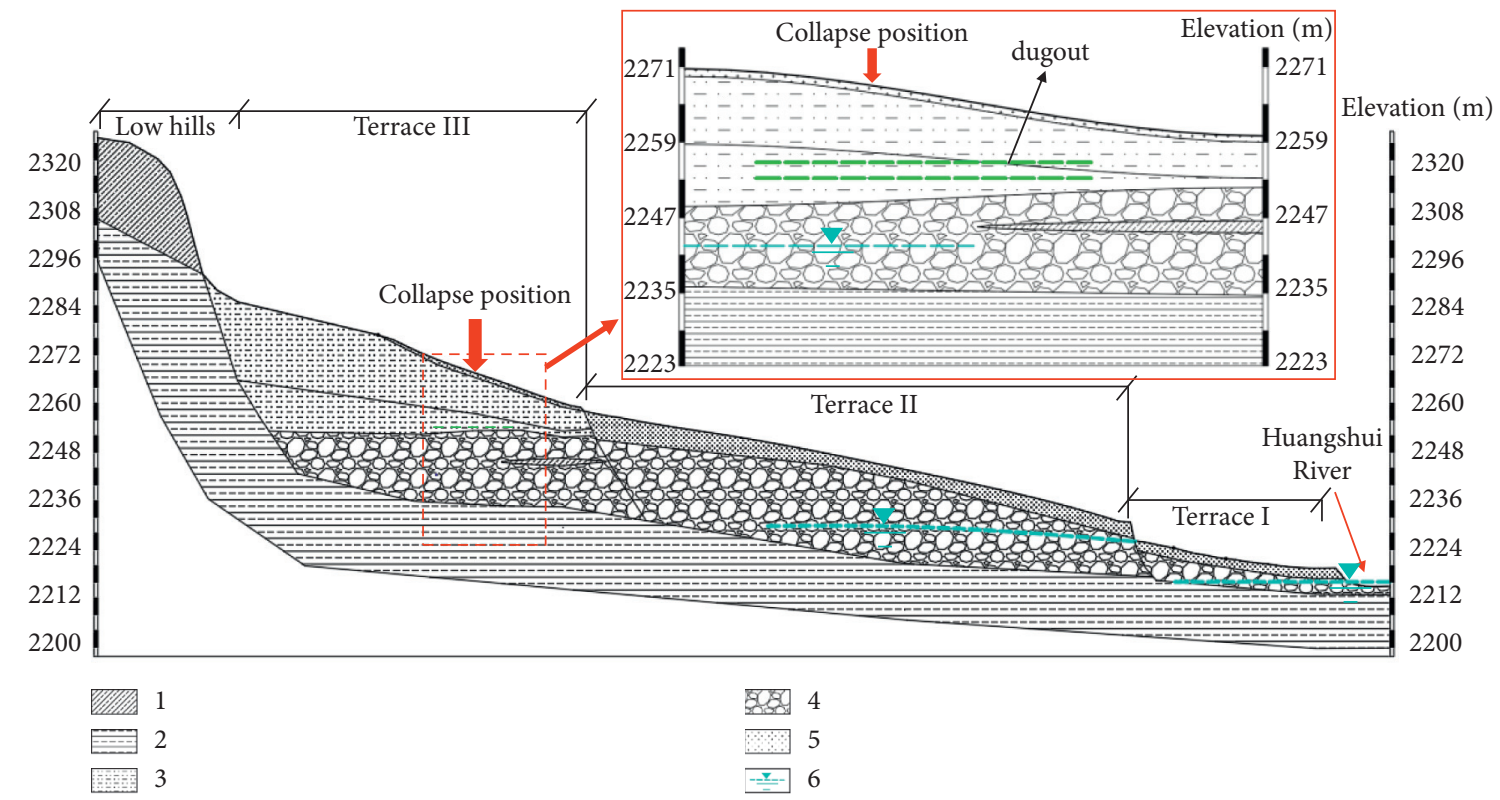

FIGURE 3: Engineering geological section. (1) Silty clay; (2) mudstone; (3) loess; (4) pebble; (5) miscellaneous fill; (6) groundwater level.

geomechanics, and based on the spatial analysis function of MAPGIS, a three-dimensional engineering geological structure model of the main urban area of Xining City is established, which stereoscopically shows the stratum situation and underground space distribution of the accident area in Figure 4.

\subsection{Analysis of the Causes of Collapse}

3.2.1. Analysis of Critical Roof Thickness of Loess Subgrade. The main stratum below the collapse area is collapsible loess soil and there are air raid shelters, so it is necessary to calculate the critical roof thickness of Loess Soil Subgrade in the collapse pit area.

The collapse equilibrium method not only considers the influence of the mechanical properties of the rock and soil but also considers the stress state of the surrounding rock of the collapse pit, especially the influence of the lateral stress. This method is suitable for the collapse pit whose shape is round or arched. According to the equilibrium condition of the collapse body, when the shear force of the rock and soil mass on the top of the collapse pit is equal to the self-weight of the upper rock and soil mass and the external additional load, the roof thickness of the collapse pit is considered as the critical thickness. The calculation model is shown in Figure 5.

According to the calculation model in Figure 5, a circular thin layer element with thickness $\mathrm{dz}$ is selected in loose rock and soil. The friction $d F$ acts on the periphery of the element. The friction $\mathrm{d} F$ of the element can be determined according to Coulomb's law:

$$
d F=2 \pi a\left(c+\sigma_{H} \tan \phi\right) d z=2 \pi a(c+\xi \gamma Z \tan \phi) \mathrm{d} z .
$$

In the above equation, $\sigma H$ is normal stress around rock and soil mass; $c$ and $\phi$ are cohesion and internal friction angle of rock and soil mass, respectively; $\xi$ is lateral pressure coefficient, $\xi=\tan ^{2}\left(45^{\circ}-\varphi / 2\right)$.

By integrating the above formula on the interval $[0, H]$, we obtain

$$
F=2 \pi a c H+\pi a \xi H^{2} \tan \phi .
$$

The overburden soil mass and additional load are as follows:

$$
G=\pi a^{2}\left(\gamma H+p_{0}\right)
$$

and when the rock and soil are in the limit equilibrium state, the critical thickness of the roof can be obtained:

$$
H_{c r}=\frac{a \gamma-2 c+\sqrt{(a \gamma-2 c)^{2}+4 a p_{0} \xi \gamma \tan \phi}}{2 \xi \gamma \tan \phi},
$$

where $a$ is collapse radius, $\mathrm{m} ; \gamma$ is gravity of rock and soil mass, $\mathrm{kN} / \mathrm{m}^{3}$; $p_{0}$ is upper uniform load, $\mathrm{kPa}$.

According to the test results of the geometric dimensions of the "1.13" pavement collapse pit and the physical and mechanical properties of loess soil in Xining City, Qinghai Province, $a=4.5 \mathrm{~m} ; \gamma=15.6 \mathrm{kN} / \mathrm{m}^{3} ; c=15 \mathrm{MPa} ; \phi=19.5^{\circ}$; $p_{0}=100 k P a$; and $H_{c r}=22 \mathrm{~m}$.

According to the calculation results, the critical thickness of the roof above the air raid shelter is about $22 \mathrm{~m}$.

According to the data, the actual thickness of the roof above the air raid shelter is about $11.6 \mathrm{~m}$, which is far less than the critical thickness of the roof, which will lead to the deformation and uneven settlement of the subgrade above the area under long-term repeated load. The thickness of the roof thinning is gradually made. Then, when the upper load 


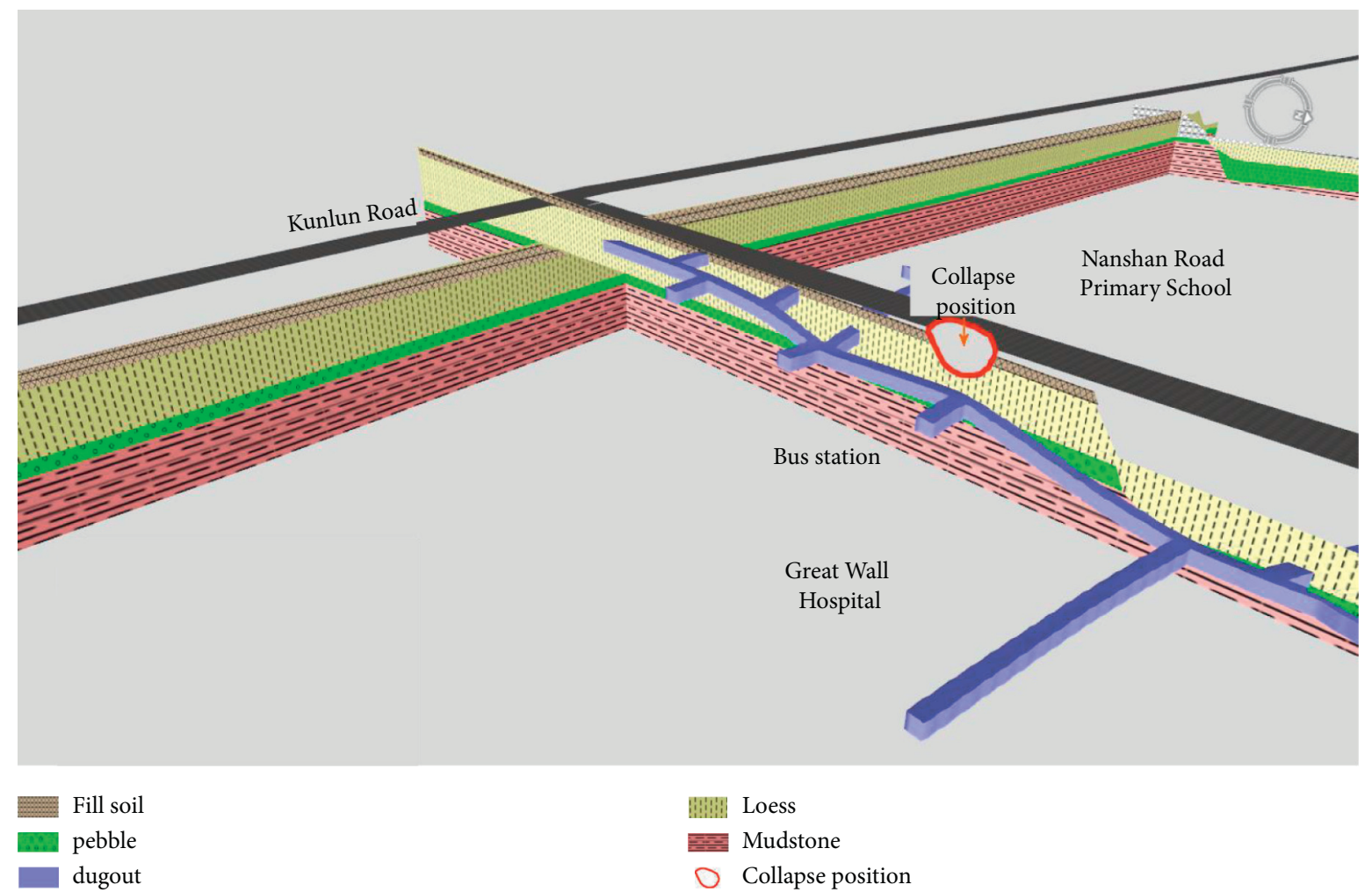

FIgURE 4: 3D geological structure model of collapse location.

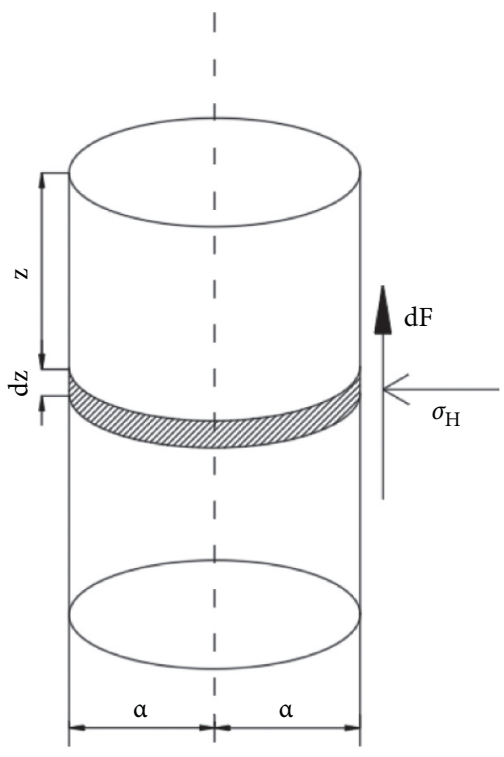

Figure 5: Calculation model of collapse balance method.

exceeds the ultimate bearing capacity of subgrade, the instantaneous collapse may occur.

3.2.2. Basic Geological Conditions. The geotechnical experiment is carried out on the soil samples obtained from the site, as shown in Figure 6. The physical and mechanical properties of collapsible loess-like soil and noncollapsible loess-like soil are mainly studied. The main physical and mechanical properties are shown in Tables 1 and 2 .

Due to the different thickness and compaction degree of the fill under the asphalt concrete cover, there is a certain degree of uneven settlement. The collapsible loess soil is the main stratum in the collapse area, with loose structure, vertical joints, macropores, and strong water sensitivity. The loess soil is collapsible, with medium to strong collapsibility, and the collapsibility grade is grade II to grade III. It is easy to dissolve the soluble salt when it is wet with water, and the particulate matter is easy to lose and the strength is reduced. This kind of stratum is the basic geological condition of road collapse.

3.2.3. Space Condition. According to the field investigation, about 400 cubic meters of water poured into the collapse pit after the underground water supply pipeline was cut off and the valve was closed. In addition, according to the geometry and size of the collapse pit, it is estimated that the loss of loess-like soil is about

$$
3.14 \times 4.52 \times 9=572 m^{3} .
$$

The total is 972 cubic meters. In addition, the total volume of water and soil mixture lost by previous leakage is more than 1000 cubic meters.

The cave body is filled with collapsing loess-like soil and gravel, and the bottom of the cave is silted. The underlying underground air raid shelter is a precast arch structure with rubble wall. Figure 7 shows the whole picture of the air raid 

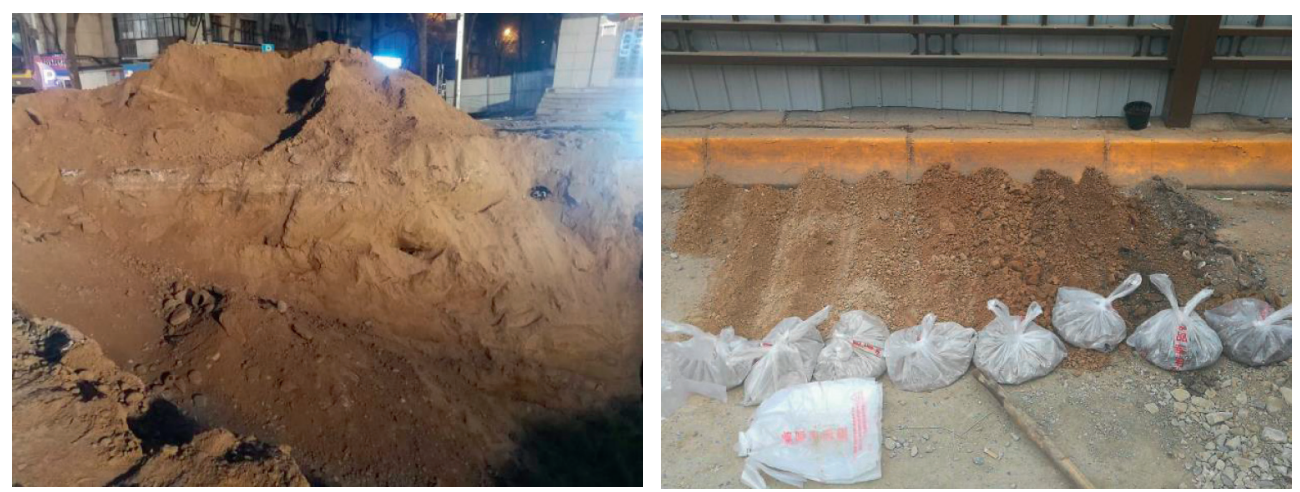

FIGURE 6: Selection of field soil samples.

TABLE 1: Statistics of physical and mechanical properties of collapsible loess (standard value).

\begin{tabular}{lccc}
\hline Natural water content & $14.44 \%$ & Compression coefficient & $0.34 \mathrm{MPa}^{-1}$ \\
Density & $1.56 \mathrm{~g} / \mathrm{cm}^{3}$ & Compression modulus & $8.20 \mathrm{MPa}$ \\
Specific gravity & 2.71 & Cohesion & $15.098 \mathrm{MPa}$ \\
Natural void ratio & 1.017 & Internal friction angle & $19.5^{\circ}$ \\
Saturation & $39.18 \%$ & Collapsibility coefficient & 0.069 \\
Liquid limit & $24.52 \%$ & Self-collapsibility coefficient & 0.008 \\
Plastic limit & $16.11 \%$ & Standard penetration value & 6.7 \\
Plasticity index & 8.44 & Liquid index & -0.19 \\
\hline
\end{tabular}

TABle 2: Statistics of physical and mechanical properties of noncollapsible loess (standard value).

\begin{tabular}{lccc}
\hline Natural water content & $21.59 \%$ & Compression coefficient & $0.39 \mathrm{MPa}^{-1}$ \\
Density & $1.82 \mathrm{~g} / \mathrm{cm}^{3}$ & Compression modulus & $11.75 \mathrm{MPa}$ \\
Specific gravity & 2.70 & Cohesion & $25.202 \mathrm{MPa}$ \\
Natural void ratio & 0.903 & Internal friction angle & $35.2^{\circ}$ \\
Saturation & $69.74 \%$ & Collapsibility coefficient & 0.008 \\
Liquid limit & $24.78 \%$ & Self-collapsibility coefficient & 0.008 \\
Plastic limit & $16.15 \%$ & Standard penetration value & 6.8 \\
Plasticity index & 8.87 & Liquid index & 0.68 \\
\hline
\end{tabular}
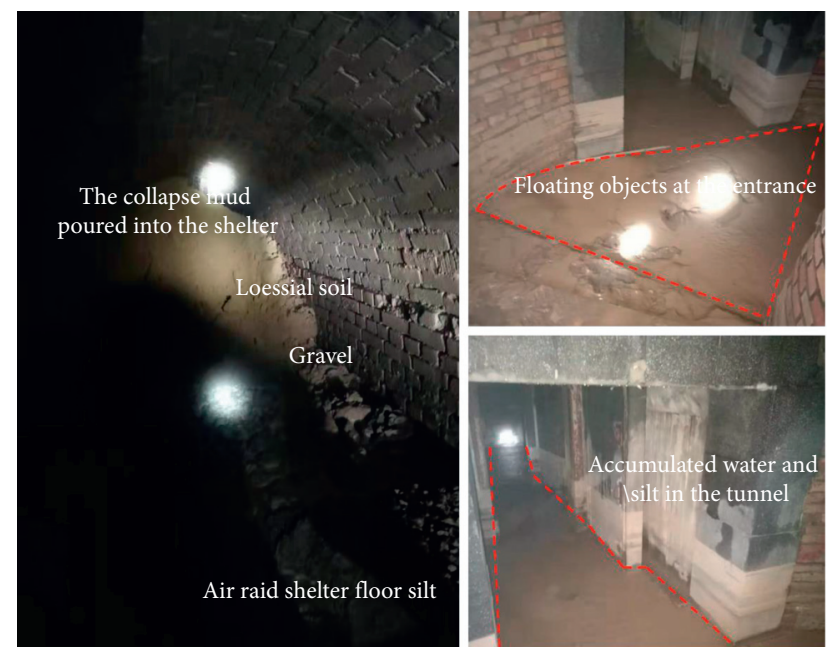

FIGURE 7: Full view of air raid shelter below after collapse.

shelter after collapse. The water depth is about $1.3 \mathrm{~m}$ and the silt thickness is about $0.5 \mathrm{~m}$.

The seepage of the top plate of the air raid shelter reduces the bearing capacity of the subgrade and provides the migration channel and storage space for the water and soil loss of the pavement before and after the collapse. The air raid shelter provided space conditions for the road collapse.

3.2.4. Leading Factor. Due to the leakage of underground water supply pipe, the collapsible loess-like soil is eroded and dissolved, the underground soil structure is destroyed, and the soil particles are lost to the air raid shelter with water and gradually develop into underground cavity body and expand to the surface, resulting in the basic suspension of the pavement and the formation of "asphalt concrete bridge," resulting in the lack of subgrade bearing capacity. The pavement is gradually damaged under the long-term repeated action of the past vehicle load, especially the sudden failure under the impact load of the large vehicle brake, which eventually leads to the bus falling into the collapse pit. Water is the main factor to form voids and cause pavement collapse.

Combined with the analysis of the above factors, it can be seen that the cause of the ground collapse accident in Xining City is that the soil under the subgrade is eroded, dissolved, and washed by the leakage of underground water supply pipe, and the soil is lost into the underground air raid shelter 
with water, resulting in the formation of large-scale cavity under the collapsed pavement, and the subgrade bearing capacity is insufficient when the bus stops, causing buses and people to fall into the collapse pit.

\subsection{Formation Process and Mechanism Analysis of Collapse.} Combined with the above data analysis, it can be seen that, before the collapse accident, the underground hidden cavity should have been formed. After the bus stops at the station, due to the insufficient bearing capacity of the surface asphalt concrete thin layer subgrade, the vehicles and personnel are trapped in the collapse pit. In order to explore the deformation and failure law of collapsible and noncollapsible loess under the effect of pipeline leakage, particle flow (PFC) was used to model the stratum. The Fluent module in ANASYS was used to calculate the groundwater flow field after pipeline leakage, and the flow field was imported into PFC for joint calculation.

3.3.1. The Establishment of the Model. According to the actual situation of the site, the mode of "subgrade and pavement + collapsible loess + noncollapsible loess + underground air raid shelter + pebble" is adopted, as shown in Figure 8. The model size is $30 \mathrm{~m} \times 1 \mathrm{~m} \times 20 \mathrm{~m}$ (length $\times$ width $\times$ height). According to the linear contact model from top to bottom, the subgrade and pavement with height of $1.5 \mathrm{~m}$, collapsible loess layer with height of $8.8 \mathrm{~m}$, noncollapsible loess layer with height of $3.6 \mathrm{~m}$, and pebble layer with height of $4.8 \mathrm{~m}$ are generated, respectively. Combined with the statistical table of physical and mechanical properties, different mechanical parameters were given to all particles in the model to exert gravity and reach equilibrium state. If the model is generated according to the actual diameter of soil particles, the number of them is far more than 100 million. In this case, it is impossible to calculate by computer. Therefore, the diameter of soil particles is expanded to $0.1 \mathrm{~m}$.

The diameter of the simulated water supply pipe is $0.5 \mathrm{~m}$, and the upper edge of the pipe is $1.5 \mathrm{~m}$ below the ground. The air raid shelter and the pipe need to be simulated with Rhino 6.0 and imported into PFC as a wall unit. The vault of the air raid shelter is $11.6 \mathrm{~m}$ deep, $2.5 \mathrm{~m}$ high, and $1.5 \mathrm{~m}$ wide. The seepage crack on the air raid shelter is assumed to be a square hole, which is located on the vault of the air raid shelter.

Fluent was used to calculate the flow field and porous medium model was used to simulate the flow field. The viscous resistance coefficient of soil was set to $6.8 \times 109$. Because of the uncertainty of the leakage location of the water supply pipe, the surface of the water supply pipe is selected as the inlet of the flow field, the velocity is set at $4 \mathrm{~m} /$ $s$, the surface of the air raid shelter is set as the outlet boundary, and the other boundaries are set as impermeable boundaries. The obtained flow field is shown in Figure 9. The flow velocity between the water supply pipe and the air raid shelter is larger than that in other areas, which is in line with the hydrodynamic properties.

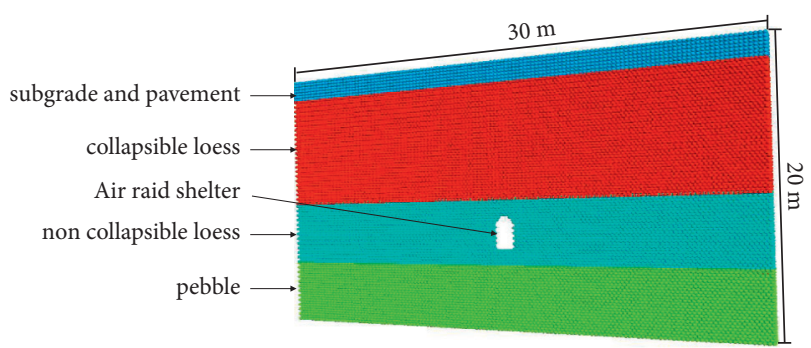

FIgURe 8: Soil model.

3.3.2. Analysis of Calculation Results. The flow field is introduced into the soil model, and PFC is used for joint calculation. The crack size on the air raid shelter model is 0.75 times of the particle size. Figure 10 shows the whole process of underground cavity formation. In the early stage of leakage, the mixture of soil and water mainly flows through the air raid shelter into the air raid shelter, so the larger disturbance area of soil is concentrated near the vault of the air raid shelter. With the progress of the calculation, the soil disturbance area continues to develop horizontally and vertically and finally extends to the ground below, forming "asphalt concrete bridge." In this case, if the pavement is repeatedly affected by external loads, and no timely discovery and remedial measures are taken, it will lead to the deformation of the pavement until sudden collapse, which poses a threat to the safety of human life and property.

In order to describe the ground settlement caused by leakage, the stratum deformation under different calculation steps is described, as shown in the figure. The calculation results show that the plastic zone tends to develop around with the progress of calculation (Figure 11). When the calculation steps are 100000, the deformation range of stratum is about $16 \mathrm{~m}$, and the height of cavity is about $9 \mathrm{~m}$. The maximum settlement occurred above the air raid shelter, and a more obvious underground cavity has been formed.

3.3.3. Void Formation Mechanism Analysis. Urban road collapse is sudden, but the formation of underground cavity has experienced the development process of water supply pipe leakage, underground soil penetration and cavity formation, critical state of collapse area, road collapse, and so on, as shown in Figure 12.

3.3.4. Leakage of Water Supply Pipe. Because the loess in this area has weak corrosivity to the concrete structure and steel structure, when the water supply pipe is buried underground for a long time and lacks effective maintenance for a long time, the corrosion leads to the leakage of the pipe wall, which makes the water flow into the lower soil layer, and the water leakage accelerates with time. Under the action of water, the soil below gradually reaches saturation state and deforms to a certain extent. At this stage, the hidden water is high, and the outflow of water in the pipe is small in a short time, which is not easy to attract the attention of the relevant departments. 


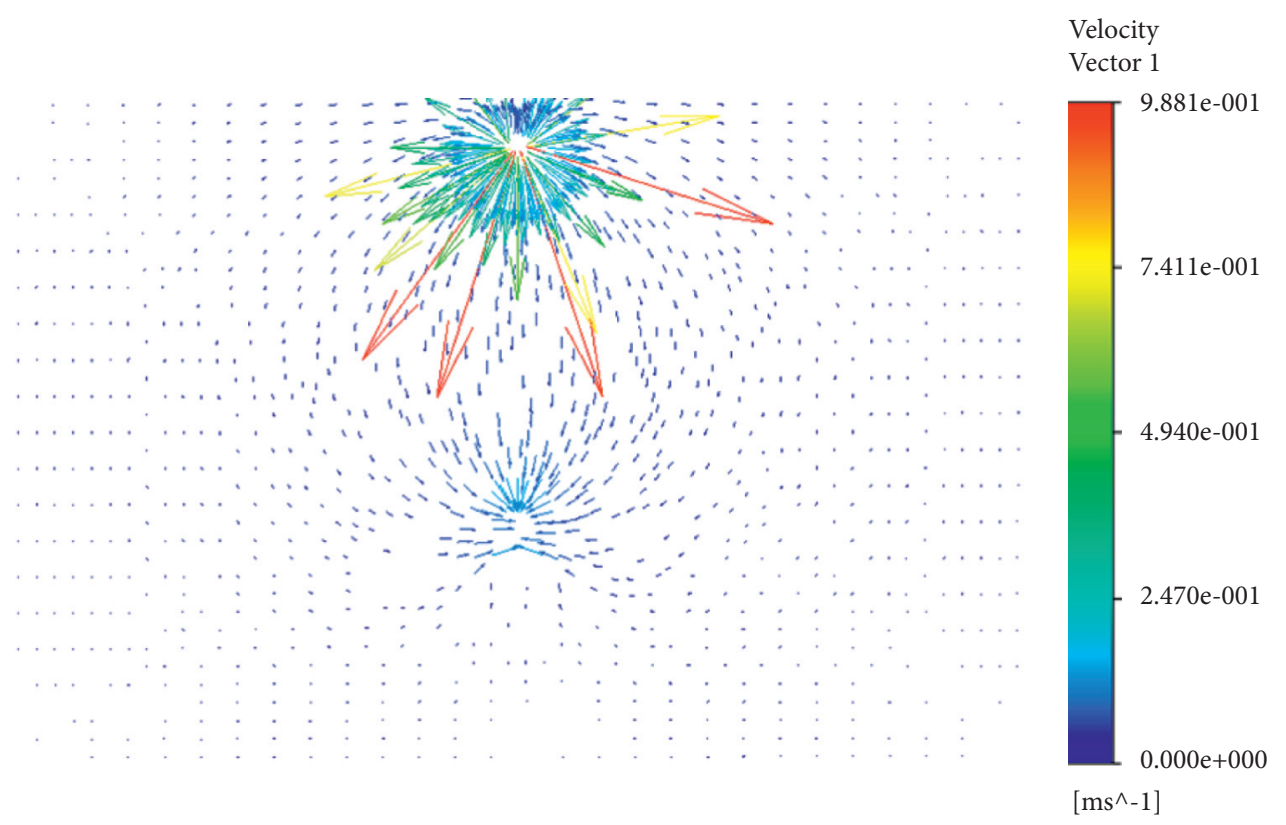

Figure 9: Flow field vector diagram.

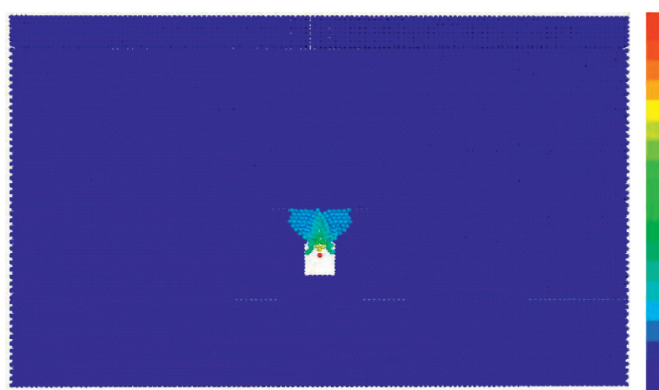

(a)

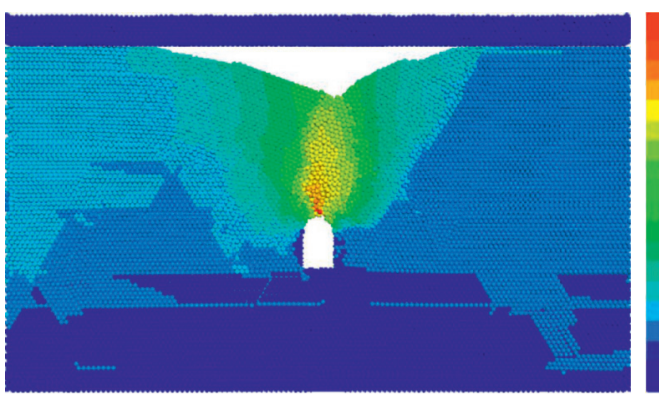

(c)

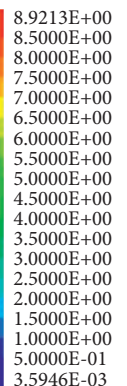

$3.0000 \mathrm{E}-01$

$.9213 \mathrm{E}+00$ $8.5000 \mathrm{E}+00$ $8.0000 \mathrm{E}+00$ $7.5000 \mathrm{E}+00$ $.5000 \mathrm{E}+00$ $.0000 \mathrm{E}+00$ $5000 \mathrm{E}+00$ $5.0000 \mathrm{E}+00$ $.5000 \mathrm{E}+00$ $.0000 \mathrm{E}+00$ $.5000 \mathrm{E}+00$ $3.0000 \mathrm{E}+00$ $.5000 \mathrm{E}+00$ $2.0000 \mathrm{E}+00$ $.5000 \mathrm{E}+00$ $.0000 \mathrm{E}+00$ 5.0000E-01

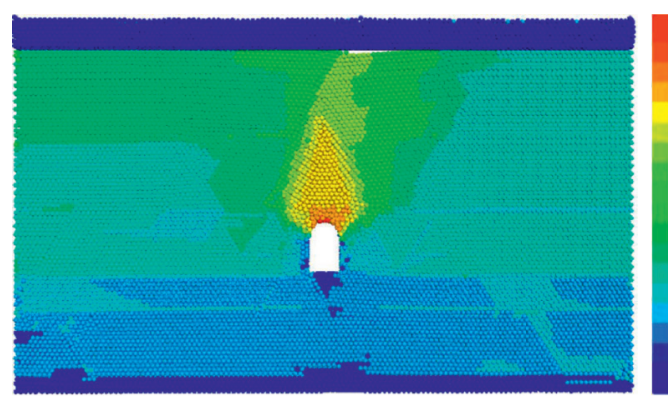

$8.9213 \mathrm{E}+00$ $8.5000 \mathrm{E}+00$ $8.0000 \mathrm{E}+00$ $7.5000 \mathrm{E}+00$ $.5000 \mathrm{E}+00$ $6.5000 \mathrm{E}+00$ $6.0000 \mathrm{E}+00$ $.0000 \mathrm{E}+00$ $4.5000 \mathrm{E}+00$ $.0000 \mathrm{E}+00$ $3.5000 \mathrm{E}+00$ $3.0000 \mathrm{E}+00$ $2.5000 \mathrm{E}+00$ $.0000 \mathrm{E}+00$ $.5000 \mathrm{E}+00$ $1.0000 \mathrm{E}+00$ $.0000 \mathrm{E}-01$

(b)

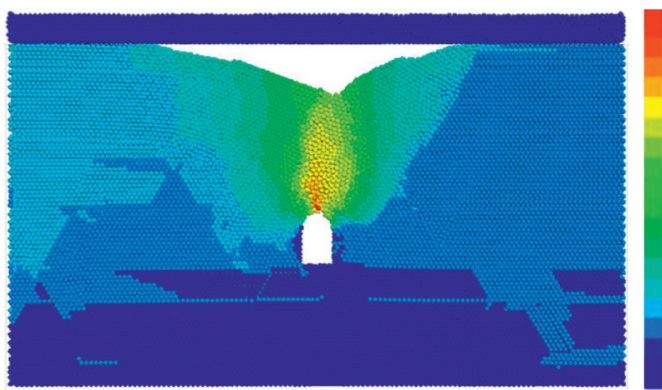

8.9213E+00 $.5000 \mathrm{E}+00$ $7.0000 \mathrm{E}+00$ $7.50000 \mathrm{E}+00$ $.5000 \mathrm{E}+00$ $.0000 \mathrm{E}+00$ $5.5000 \mathrm{E}+00$ $5.0000 \mathrm{E}+00$ $4.5000 \mathrm{E}+00$ $4.0000 \mathrm{E}+00$ $.5000 \mathrm{E}+00$ $3.0000 \mathrm{E}+00$ $2.5000 \mathrm{E}+00$ $.0000 \mathrm{E}+00$ $.5000 \mathrm{E}+00$ $1.0000 \mathrm{E}+00$
$5.0000 \mathrm{E}-01$ $5.0000 \mathrm{E}-01$
$3.5946 \mathrm{E}-03$

(d)

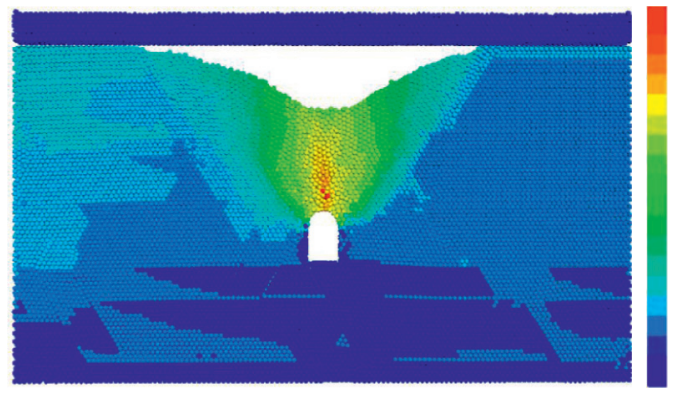

$8.9213 \mathrm{E}+00$ $8.0000 \mathrm{E}+00$ $7.5000 \mathrm{E}+00$ $7.0000 \mathrm{E}+00$ $6.5000 \mathrm{E}+00$ $6.0000 \mathrm{E}+00$ $5.5000 \mathrm{E}+00$ $5.0000 \mathrm{E}+00$ $4.5000 \mathrm{E}+00$ $4.0000 \mathrm{E}+00$ $3.5000 \mathrm{E}+00$ $2.5000 \mathrm{E}+00$ $2.50000 \mathrm{E}+00$ $2.0000 \mathrm{E}+00$
$1.5000 \mathrm{E}+00$ $1.0000 \mathrm{E}+00$ $5.0000 \mathrm{E}-01$
$3.5946 \mathrm{E}-03$

(e)

Figure 10: Displacement cloud map of each soil layer in the stratum. (a) Run 5000 steps. (b) Run 10000 steps. (c) Run 30000 steps. (d) Run 80000 steps. (e) Run 100000 steps. 


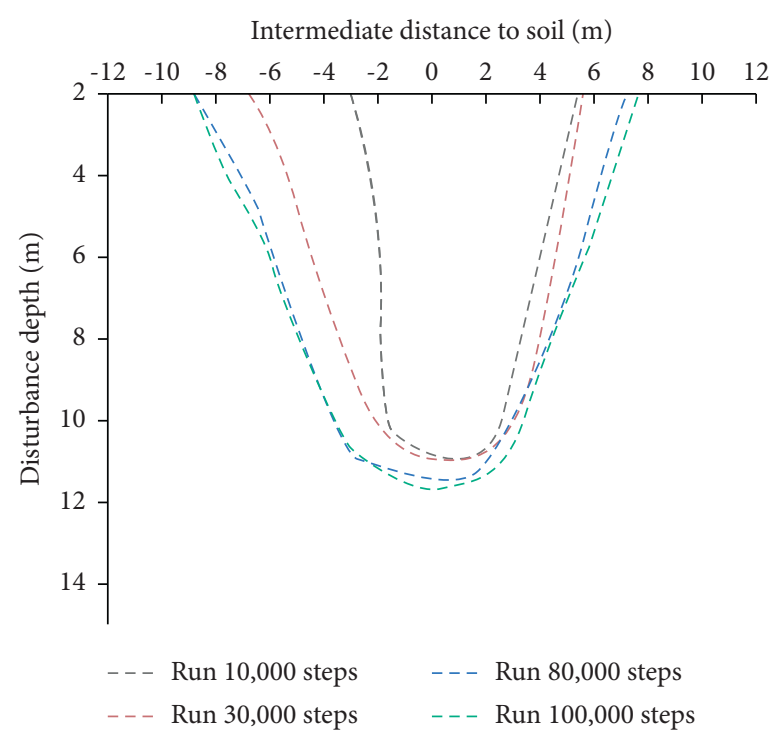

(a)

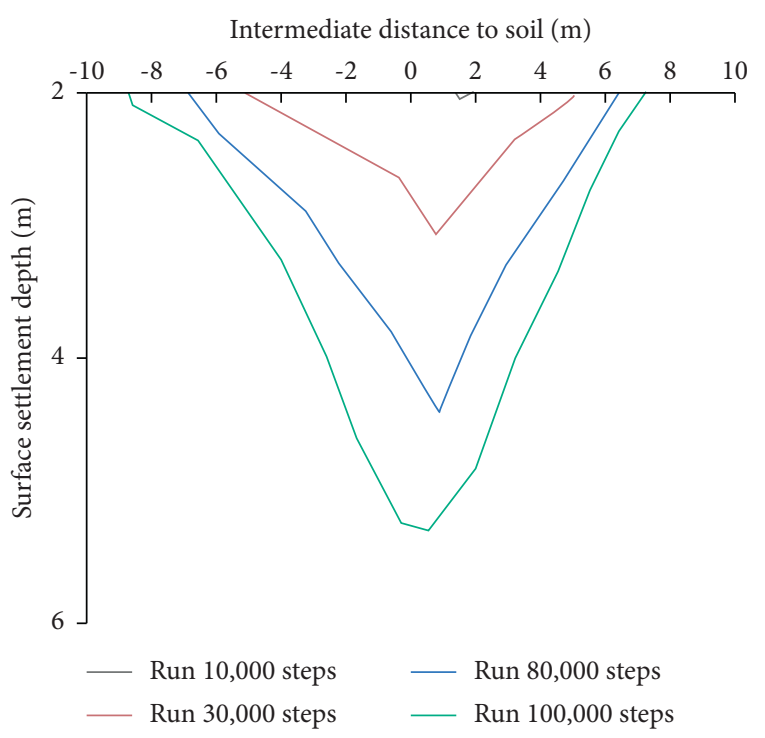

(b)

FIGURE 11: Envelope of disturbance zone and surface settlement curve. (a) Envelope of disturbed region. (b) Surface subsidence curve.

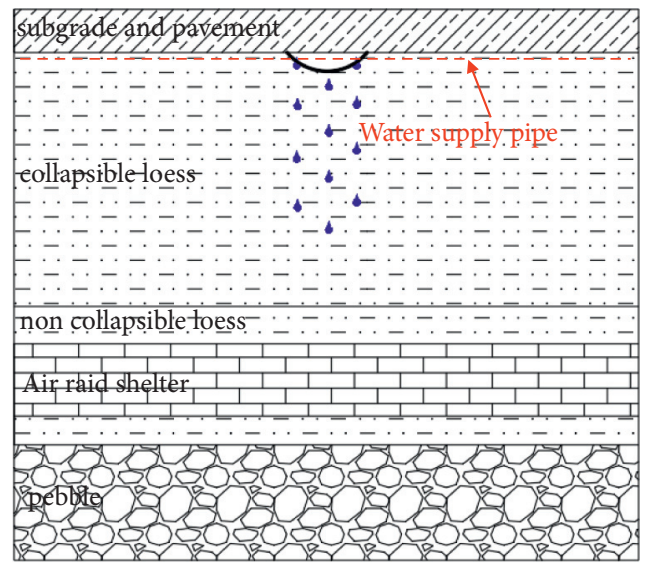

(a)

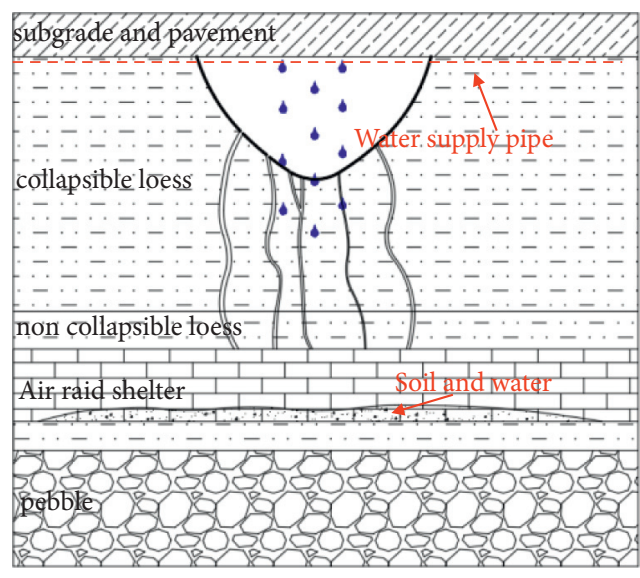

(c)

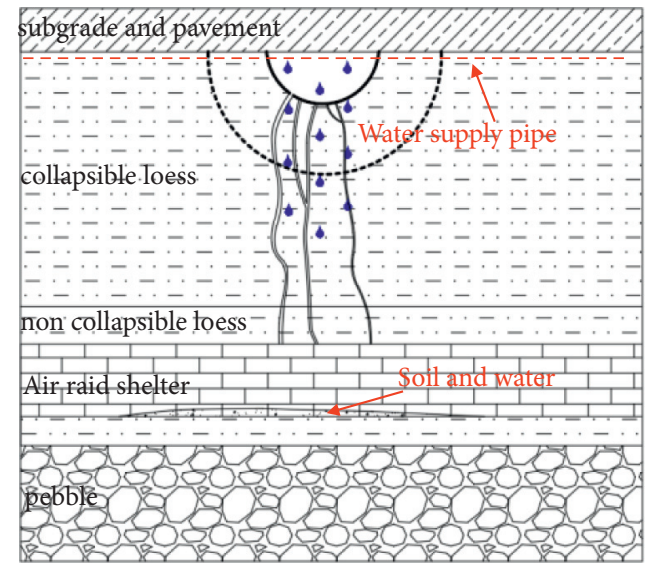

(b)

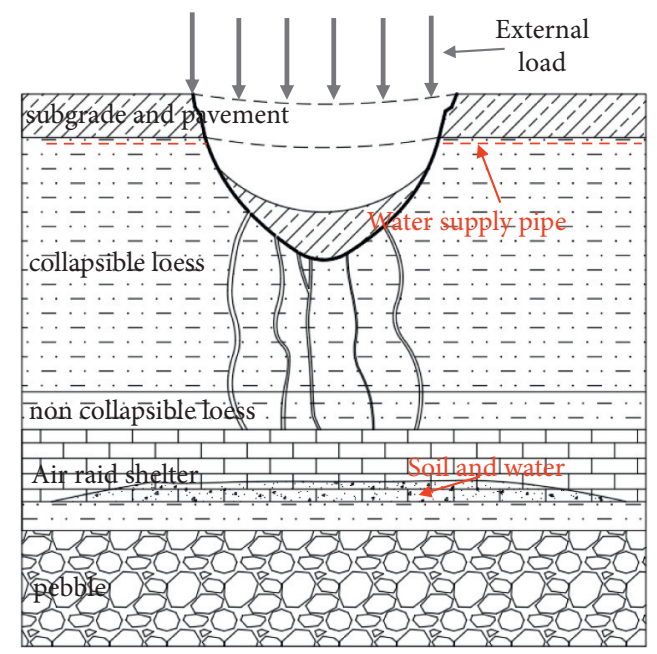

(d)

FIGURE 12: Formation and collapse process of underground cavity. (a) Leakage. (b) Development. (c) Through. (d) Collapse. 
3.3.5. Penetration of Underground Soil and Formation of Cavities. On the one hand, the long-term water leakage will accelerate the corrosion of the water supply pipe, thus speeding up the water leakage in the water supply pipe. On the other hand, the fine particles in the soil are taken away and flow into the air raid shelter under the action of water, forming "underground passages" at the initial stage, which connect and expand with each other, eventually leading to the formation of underground cavities. At the same time, because of the collapsibility of the loess in this area, the collapsibility effect will occur when it meets with water, which will also cause the uneven settlement of the soil at the leakage and accelerate the formation of underground cavities.

3.3.6. Critical State of Collapse Zone. With the formation, transfixion, and expansion of underground cavity, coarse particles in soil exist in the form of skeleton, and soil structure also changes to some extent. However, soil can still maintain a critical stable state through its skeleton effect and stress adjustment. When this stable state is disturbed by external factors, it is easy to lose stability.

3.3.7. Road Collapse. The collapse area is in a critical state, forming "Asphalt Pavement Bridge." When the bus and other external loads act on the pavement, the external load reaches and exceeds the ultimate bearing capacity of the subgrade, and the pavement collapses suddenly.

\section{Conclusions and Suggestions}

(1) The accidental factor causing the ground collapse accident is the water from the water supply pipe and once again confirmed that the urban ground collapse disaster has the characteristics of high concealment and sudden and high risk.

(2) Numerical simulation analysis shows that the final stratum deformation range is about $16 \mathrm{~m}$, and the height of the cavity formed at this time is about $9 \mathrm{~m}$. The maximum settlement occurred above the air raid shelter, and a more obvious underground cavity has been formed.

(3) The process of ground collapse includes four stages: water supply pipe leakage, underground cavity formation, critical state of ground collapse, and ground collapse.

(4) It is suggested that Xining City should adopt various means as soon as possible to carry out exploration and safety risk assessment on various underground pipe networks and air raid shelters of urban roads and do a good job in the daily operation, maintenance, management, monitoring, and early warning of underground pipe networks to avoid similar incidents in Xining area. At the same time, it should also sound an alarm to the whole country and strengthen the planning, development, and utilization, comprehensive management, and underground disease prevention and control of urban underground space in the whole country.

\section{Data Availability}

The data are available and explained in this article; readers can access the data supporting the conclusions of this study.

\section{Conflicts of Interest}

The authors declare no conflicts of interest.

\section{Acknowledgments}

The authors gratefully acknowledge the funding provided by National Key R\&D Program of China (2019YFC1509600).

\section{References}

[1] S. Yi, "Distribution characteristics of ground collapse and its countermeasures Guangdong Province[J]," Chinese Journal of Geological Hazard and Control, vol. 2007, no. 02, pp. 127-131, 2007.

[2] M. Yan, K. Yin, and M. Lei, "Probabilistic analysis ON karst collapse induced BY water ta fluctuation [j]," Carsologica Sinica, vol. 2006, no. 03, pp. 239-241+245, 2006.

[3] Y. Shengquan, "Formation causes of Karst collapse and its preventing measures in Guizhou Province [J]," Science of Soil and Water Conservation, vol. 2007, no. 06, pp. 38-42, 2007.

[4] G. Chen, Y. Wang, and W. Zhou, "The formation research of karst caves in Wushan copper mine JiangXi province [J]," China Water Transport(Academic Version), vol. 2007, no. 10, pp. 95-97, 2007.

[5] Y. Zhao and Y. Xie, "Discussion on the cause and mechanism of Goaf collapse in xinzhou mine, guangxi [J]," Chinese Journal of Geological Hazard and Control, vol. 1997, no. S1, pp. 204-211, 1997.

[6] H. Huang, Y. Wu, G. Lv, and L. liang, "Cause analysis and prevention methods of Goaf collapse in datong coal mine [J]," China Energy and Environmental Protection, vol. 2009, no. 01, pp. 26-27+40, 2009 .

[7] W. Ji and X. Yin, "Cause mechanism and prevention strategy of mining collapse disaster [J]," Chinese Journal of Geological Hazard and Control, vol. 1998, no. 03, pp. 60-65, 1998.

[8] J. Sun, "Collapsibility of loess and its relationship with humidity [J]," Hydrogeology \& Engineering Geology, vol. 1957, no. 11, pp. 18-21, 1957.

[9] Z. Zhang, "Study on Microstructure of loess like soil in China [J]," Acta Geologica Sinica, vol. 1964, no. 03, pp. 357-369+375, 1964.

[10] G. Gao, "Discussion on microstructure and collapsibility mechanism of lanzhou loess [J]," Journal of Lanzhou University, vol. 1979, no. 02, pp. 123-134, 1979.

[11] G. Gao, "Relationship between microstructure, geography and geological environment of loess in China [J]," Acta Geologica Sinica, vol. 1984, no. 03, pp. 265-280, 1984, $272+279-$

[12] C. Hou, M. Dong, and H. Fu, "Research on genesis and mechanics of land collapse in incompact soil [J]," Journal of Hefei University of Technology, vol. 36, no. 01, pp. 63-67, 2013.

[13] C. Gu, C. Yuan, and R. Qing, "Subsidence causation and countermeasure analysis of urban roads in beijing [J]," Urban 
roads and bridges and flood control, vol. 2011, no. 08, pp. 250-252+9, 2011.

[14] Y. Jiang, G. Yang, Z. Huang, Y. Qiao, and Y. Zhang, "Ground treatment of high-rise buildings in complex karst region, [J]," Rock and Siol Mechanics, vol. 36, no. S1, pp. 430-438, 2015.

[15] Y. Yechieli, M. Abelson, and G. Baer, "Sinkhole formation and subsidence along the Dead Sea coast, Israel," Hydrogeology Journal, vol. 24, no. 3, pp. 1-12, 2015.

[16] Z. Cheng, "Effects of irrigation on land subsidence and ecological environment in Loess Plateau area of central Gansu Province[J]," Journal of Desert Reseaech, vol. 2002, no. 02, pp. 76-80, 2002.

[17] C. xing and S. Peng, "Numerical simulation of collapse caused by groundwater level decline in Karst Area[J]," Earth and Environment, vol. 33, no. s1, pp. 119-123, 2005.

[18] Z. Wan, S. Qin, Z. Li, and H. Qian, "Formation mechanism and initial condition of soil cavity [J]," Journal of rock mechanics and Engineering, vol. 22, no. 8, pp. 1377-1382, 2003.

[19] A. N. Palmer and M. V. Palmer, "Hydraulic processes in the orgin of tiankengs[J]," Carsologica Sinica, vol. 25, no. s1, pp. 71-78, 2006.

[20] G. Selleri, P. San $\widetilde{\text { ô }}$, and N. Walsh, "The karst of Salento region (apulia, southern Italy): constraints for management[J]," Acta Carsologica, vol. 32, no. 1, 2016.

[21] Z.-h. Ouyang, "The role of potential soil cavity on ground subsidence and collapse in coal mining area," Journal of Coal Science and Engineering, vol. 16, no. 3, pp. 240-245, 2010.

[22] F. Cao, "Causes and prevention of karst ground collapse in Zaozhuang area [J]," Carsologica Sinica, vol. 1998, no. 2, pp. 104-110, 1998.

[23] T. Peng, S. Ge, and W. Wu, "Remeadiations of foundation collapse in the soil cavity area of karst [J]," Hydrogeology \& Engineering Geology, vol. 28, no. 3, pp. 55-57, 2001.

[24] Z. Gao, "Study on the mechanism and cause mode of the karst collapse-_taking tai'an-laiwu for example [J]," Strategic Study of CAE, vol. 2008, no. 04, pp. 38-43, 2008.

[25] Z. Hu, "Formation mechanism and prevention of surface subsidence in East mining area of Tangshan City [J]," Hydrogeology \& Engineering Geology, vol. 1991, no. 4, pp. 34-36, 1991.

[26] X. Li, K. Peng, J. Peng, and D. Hou, "Experimental investigation of cyclic wetting-drying effect on mechanical behavior of a medium-grained sandstone," Engineering Geology, vol. 293, Article ID 106335, 2021.

[27] X. Li, K. Peng, J. Peng, and H. Xu, "Effect of cyclic wettingdrying treatment on strength and failure behavior of two quartz-rich sandstones under direct shear," Rock Mechanics and Rock Engineering, vol. 54, no. 11, pp. 5953-5960, 2021.

[28] S. TÜRkmen and N. ÖZgÜZel, "Grouting a tunnel cave-in from the surface: a case study on Kurtkulağ 1 irrigation tunnel, Turkey," Tunnelling \& Underground Space Technology Incorporating Trenchless Technology Research, vol. 18, no. 4, pp. 365-375, 2003.

[29] Y. Hou, D. Zhang, and P. Li, "Analysis and control measures of safety accidents in beijing subway construction [J]," Journal of Beijing Jiaotong University, vol. 2009, no. 3, pp. 52-59, 2009.

[30] H. Ma, X. Wang, W. You, and P. Che, "Cause analysis on the ground collapses during the launching period of a Metro shield [J]," Modern Tunnelling Technology, vol. 47, no. 03, pp. 76-80, 2010.

[31] C. Zhu, Z. Yan, Y. Lin, F. Xiong, and Z. Tao, "Design and application of a monitoring system for a deep railway foundation pit project," IEEE Access, vol. 7, pp. 107591-107601, 2019.
[32] C. Zhu, K. Zhang, H. Cai et al., "Combined application of optical fibers and CRLD bolts to monitor deformation of a pitin-pit foundation," Advances in Civil Engineering, vol. 2019, no. 1, pp. 1-16, 2019. 